\title{
Development and Characterization of Leuprolide Acetate Encapsulated PLGA Microspheres for Parenteral Controlled Release Depot Injection
}

\author{
Soumya Ranjan Satapathy ${ }^{1}$, Rudra Narayan Sahoo, ${ }^{1,2}$, Biswaranjan Satapathy ${ }^{3}$, \\ Ramachandrarao Immani ${ }^{4}$, Lalatendu Panigrahi ${ }^{5}$, Subrata Mallick ${ }^{1, *}$ \\ 'School of Pharmaceutical Sciences, Siksha 'O' Anusandhan (Deemed to be University), Bhubaneswar, Odisha, INDIA. \\ ${ }^{2}$ School of Pharmacy and Life Sciences, Centurion University of Technology and Management, Odisha, INDIA. \\ ${ }^{3}$ Orbicular Technologies Pvt Ltd, Mumbai, Maharashtra, INDIA. \\ ${ }^{4}$ Department of Chemistry, Annamalai University, Chidambaram, Tamil Nadu, INDIA. \\ ${ }^{5}$ Encube Ethicals Pvt Ltd, Mumbai, Maharashtra, INDIA.
}

\begin{abstract}
Objectives: Polylactic acid (PLA) and copolymer polylactic-co-glycolic acid (PLGA) are the most versatile drug carriers for long acting release injectable (LAI) formulations for small molecules, peptides and macromolecules such as proteins and nucleic acids. The present research work consists of a PLGA based one-month release microsphere formulation of $\mathrm{GnRH}$ agonist leuprolide acetate, using double emulsion $\left(\mathrm{W}_{1} / \mathrm{O} / \mathrm{W}_{2}\right)$ technique. Materials and Methods: Microparticles were prepared by double emulsion solvent evaporation technique and critical quality attributes of finished products such as drug loading, entrapment efficiency, particle size distribution (PSD), surface porosity, drug distribution within microparticles were analysed. Results and Conclusion: The microspheres have shown the mean particle size of $15.2 \mu \mathrm{m}$ and suitable particle size distribution pattern ideal for syringe ability. The microparticles were spherical in shape with uniform pore distribution and uniform distribution of API in the polymer matrix. The drug release has been sustained over a month for the microsphere formulation and could be correlated with the testosterone suppression.
\end{abstract}

Key words: Leuprolide, PLGA Microspheres, Double-emulsion technique, Prostate cancer, Controlled release depot Injection.

\section{INTRODUCTION}

Prostate cancer is one of the primary causes of cancer related mortality among men. The difficulty in early detection and improper screening techniques, make the primary stage unnoticed. ${ }^{1,2}$ The treatment strategies include a combination of surgery, radiation therapy, hormone therapy or chemotherapy. ${ }^{3}$ However, the exponential rise in prostate cancer cases globally witnessed the evidence of the failure of current therapy which left the formulation scientist to think for alternative therapeutics. In this context PLGA microspheres are gaining increasing attention due to ease in fabrication and ability of releasing the active ingredient from several weeks to months by modulating formulation aspect. The application of controlled drug delivery carriers is offering many exciting possibilities in the management and successful treatment of prostate cancer due to their much superiority over conventional formulations. Microparticulate drug delivery system is the most reliable and widely accepted delivery platform for parenteral controlled release depot injections. Hence, it has been commercialized in more than a dozen of marketed formulations for different therapeutic segments. $^{4}$

Gonadotropin-releasing hormone (GnRH) agonists have a scientifically and clinically established role in the therapeutic regimen
Submission Date: 29-07-2020; Revision Date: 23-09-2020; Accepted Date: 16-10-2020

DOI: 10.5530/ijper.55.1.14 Correspondence: Prof. Subrata Mallick Department of Pharmaceutics, School of Pharmaceutical Sciences, Siksha 'O' Anusandhan, (Deemed to be University), Bhubaneswar-751003, Odisha, INDIA.

Phone no: +919861164058 Email id: profsmallick@ gmail.com

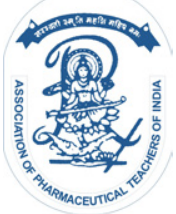

www.ijper.org 
of hormone-sensitive cancers such as prostate cancer and breast cancer. When injected, these analogues stimulate the luteinizing hormone (LH) and follicle stimulating hormone (FSH) production, which in turn send message to hypothalamus and anterior pituitary to suppress the sex hormones in both males and females. Thus these agonists when administered at a higher dose for a longer period of time act by negative feedback mechanism to suppress the levels of testosterone and dihydro testosterone, responsible for the growth of prostate cancer cells in males and similarly oestrogen and progesterone, responsible for the growth of endometriosis in females. This down regulation can be maintained for a long period with medication and reversible in nature when the treatment is stopped. The discovery and development of GnRH agonist was a great help for patients suffering from cancers caused by increased levels of hormones, such as prostate cancers. ${ }^{5-10}$ One of such highly effective and widely used GnRH agonist is leuprolide acetate which holds significant market share in the controlled release peptide injectable. ${ }^{11-13}$ But it suffers from the disadvantages of short elimination half-life of 3-4 $\mathrm{h}$ and frequent administration via subcutaneous or intramuscular route. ${ }^{14}$ Lupron Depot ${ }^{\circledR}$ (LD) containing hydrophilic leuprolide acetate in PLGA microspheres was the first, once a month depot injectable launched in the US market to overcome this issue. ${ }^{15}$ Although the patent got expired for a long period of time, no generic formulation has been approved in the USA due to complexity in the manufacturing techniques and process optimization. Thus, the present research work aimed to manufacture and characterize once a month release formulation containing leuprolide acetate loaded PLGA microsphers as the platform for parenteral controlled release depot injection. One-month release injectable microspheres of leuprolide injection have been published earlier (1989 and 1991) but in vitro drug release study has not been reported in the papers. ${ }^{16,17}$ In-vivo drug release has only been estimated at $24 \mathrm{~h}$ and onward (1989). ${ }^{16}$ The availability of the drug in vivo within first $24 \mathrm{~h}$ is very important in sustained release product and that is missing in the paper. The objective of this research article is to focus on how raw materials and manufacturing process variables affect the critical quality attributes of the finished formulation such as residual solvent, particle size distribution and in vitro release etc. Residual solvent has not been reported earlier publications of Ocada. ${ }^{16,17}$ Subsequently, the results described here could help on the development of a generic version of LD as well as PLGA based new controlled release formulations containing peptides.

\section{MATERIALS AND METHODS}

\section{Materials}

Leuprolideacetate and PLGA (copolymer ratio 75:25; molecular weight $12 \mathrm{kDa}$; inherent viscosity $0.17 \mathrm{dL} / \mathrm{g}$ ) were obtained as gift sample fromExcimed, Hyderabad. Other excipients such as gelatine, polyvinyl alcohol 8-88 (mW- 67,000), D-mannitol, methylene chloride, polysorbate 80 , glacial acetic acid, carboxymethylcellulose sodium were procured from Merck Life Science Private Limited, Mumbai. All these raw materials were of pharmaceutical grade.

\section{Preparation of microspheres}

Multiple Emulsion $\left(\mathrm{W}_{1} / \mathrm{O} / \mathrm{W}_{2}\right)$ also known as double emulsion solvent evaporation technique was used to prepare the leuprolide acetate loaded microspheres. This manufacturing technology is highly sophisticated, complex and dozens of critical process parametres need to be optimized to get desired product profile. ${ }^{18}$ The information regarding the quantities of PLGA, Leuprolide acetate and other raw materials for a single unit is mentioned in the pack insert and quantity for a 100 unit batchis calculated accordingly. ${ }^{15}$

\section{Preparation of Oil Phase (0)}

PLGA polymer was accurately weighed $(3310 \mathrm{mg})$ in a $20 \mathrm{~mL}$ beaker and $5 \mathrm{~mL}$ of dichloromethane was added inside the beaker through a Pipette. The beaker was closed immediately to prevent evaporation. It was soaked for $2 \mathrm{hr}$ with occasional sonication to make it homogeneous and clear. This phase is known as oil phase $(\mathrm{O})$.

Polymer concentration is of paramount significance to manipulate emulsion viscosity, particle size and encapsulation efficiency, hardening time, porosity pattern and initial burst release. ${ }^{19-23}$

\section{Preparation of External aqueous Phase $\left(\mathrm{W}_{2}\right)$}

Distilled water $(1.5 \mathrm{~L})$ was takenand $3 \mathrm{~g}$ of polyvinyl alcohol (PVA) was added into it. It was mixed well at moderate speed for 20-30 min. It was placed at $15^{\circ} \mathrm{C}$ for $2 \mathrm{hr}$ (until the temperature reaches in between $18-20^{\circ} \mathrm{C}$ ). This phase was known as outer water phase (W2). PVA was used in the outer water phaseas a colloidal protector to make a stable double emulsion by preventing the aggregation of the semi dry microspheres. The concentration of PVA influences emulsion stabilization, particle size and sphericity index of the finished microspheres. ${ }^{24-28}$ 


\section{Preparation of internal aqueous phase $\left(\mathrm{W}_{1}\right)$}

In a test tube containing $9 \mathrm{~mL}$ of water $1.2 \mathrm{~g}$ gelatine was heated at $50^{\circ} \mathrm{C}$ with occasional vortexing for homogenous mixing. It was filtered through a syringe driven filter (0.22 u PVDF filter). Gelatin solution containing $525.5 \mathrm{mg}$ was taken in a wide mouth test tube and $387.5 \mathrm{mg}$ of leuprolide acetate (equivalent to $375 \mathrm{mg}$ leuprolide base) was added into the test tube and vortexed until it becomes homogenous. This phase was known as internal aqueous phase (W1). Gelatine plays a critical role by increasing the viscosity of the internal aqueous phase which led to the high entrapment efficiency, thus the grade and bloom strength is carefully selected. The volume of W1 is very important for the stabilization of primary emulsion..$^{29,30}$

\section{Preparation of Primary emulsion $\left(\mathrm{W}_{1} / 0\right)$}

Oil phase $(\mathrm{O})$ was added into the aqueous phase $\left(\mathrm{W}_{1}\right)$ and homogenization was done for 1 min through bench top homogenizer at rpm 10,000. This was known as primary emulsion $\left(\mathrm{W}_{1} / \mathrm{O}\right)$. It was covered immediately with lid to prevent evaporation and kept at $15^{\circ} \mathrm{C}$ for stabilization for half an hour. The cooling of primary emulsion increased the viscosity of the formulation. This higher viscosity led to the higher encapsulation efficiency. ${ }^{6,7}$ Volume of primary emulsion influences the surface porosity and loss of peptide during secondary emulsification. ${ }^{29,30}$

\section{Preparation of Double emulsion $\left(\mathrm{W}_{1} / \mathrm{O} / \mathrm{W}_{2}\right)$}

The stabilized water-in-oil emulsion $\left(\mathrm{W}_{1} / \mathrm{O}\right)$ was checked for temperature to be maintained in the range of $14 \pm 2^{\circ} \mathrm{C}$. This was injected into the outer water phase $\left(\mathrm{W}_{2}\right)$ very slowly for 2-3 min to form the multiple emulsion or double emulsion $\left(\mathrm{W}_{1} / \mathrm{O} / \mathrm{W}_{2}\right)$. Injection time and post injection stirring time were critically observed during each trial and optimized. Solvent removal was carried out by continuous nitrogen purging and increasing temperature gradually from $20-35^{\circ} \mathrm{C}$. Filtration was carried out by $5 \mu$ poly ether sulphone (PES), $127 \mathrm{~mm}$ diameter Millipore filter through a Buchner funnel and bench top filtration assembly. On the top of the Buchner funnel $75 \mu \mathrm{m}$ sieve (prefilter) was used to remove the coarser microparticles. It was cleaned with enough water (approximately 2-3 L) for complete PVA removal. The microspheres were collected and dried. The yield of the microsphere was found to be $80 \%$. Mannitol was weighed $528 \mathrm{mg}$ instead of $660 \mathrm{mg}$ considering $80 \%$ yield of microsphere and dissolved it in $100 \mathrm{~mL}$ of water. After dispersing the microsphere in mannitol, dispersion was transferred into the SS 316 made round lyophilization tray. After lyophilization, the product was filled into vials at low humidity area under Laminar Air
Flow (LAF) and sealed properly. ${ }^{31}$ Methylene Chloride (DCM), Polyvinyl Alcohol (PVA) and distilled water were used in the manufacturing process and hence not a part of the final formulation.

\section{Pre-formulation studies}

\section{Fourier transforms infrared spectroscopy (FTIR)}

The pure drug, individual raw materials and a mixture of both of them, were mixed (physical mixture) with IR gradedried potassium bromideinthe proportion of 1:100 and to make a transparent pellet compressed at 20,000-25,000 psi in a hydraulic press. Then the sample was scanned in the range of 4000-450 cm-1using FT-IR spectrophotometer (Perkin Elmer-Spectrum 100 is the software used for data collection)..$^{32}$

\section{DSC analysis}

Interactions can be detected in DSC based on presence and absence of endothermic peaks. DSC experiments were performed by a DSC mode 1821 (Mettler-Toledo, Switzerland). All accurately weighed samples of polymer and API at different proportions were placed properly inside sealed pans made up of aluminium. Heating was performed under nitrogen flow at $20 \mathrm{~mL} / \mathrm{min}$ and scanning at the rate of $10^{\circ} \mathrm{C}$ per min. DSC thermograms of microspheres, polymers and complexes were recorded. ${ }^{33}$

\section{Physicochemical characterization of the drug loaded microspheres \\ SEM analysis}

For surface topography characterization, scanning electron microscopy was used for the finished microparticles (Hitachi, TM3030Plus). The reconstituted microparticles were properly distributed on the surface of carbon tape over the SEM stub. Once the vacuum-driyng was accomplished, the sample was coated with a very fine layer of gold through an ion sputting device. Then the samples were vacuum dried and scanning was performed on the microspheres surface and photomicrographs were produced by electron microscope.

\section{High resolution Scanning Electron Microscopy}

High resolution scanning electron microscopy (JEOL JSM-7800FLV) was performed and colour images with proper contrast and resolution was obtained. This was immensely helpful for understanding the API distribution in the polymer matrix, PLGA distribution and the intense drug domains inside the microspheres.

\section{Determination of particle size}

A small amount of freeze-dried microsphere was redisposed in distilled water and their size was measured 
in Master sizer 3000 (Make: Malvern) by using the laser diffraction technique. The samples were dispersed in a medium volume liquid cell. When the laser beam was passed inside the cell, the dispersed particles scattered the light with a pattern. The helium neon laser beam calculates the intensity and angles of scattered light from which particle size distribution was measured in micrometre range.

\section{Determination of Percentage yield and Entrapment efficiency}

Microsphere prepared were weighed after lyophilization and percent yield was measured using the following formula.

$$
\text { Percentage yield }=\left(\frac{\text { Actual weight }}{\text { Theoretical weight }}\right) \times 100
$$

In order to determine the entrapment efficiency, microparticles equivalent to $10 \mathrm{mg}$ of leuprolide acetate were mixed with $10 \mathrm{~mL}$ of $6.8 \mathrm{pH}$ phosphate buffer. This mixture was placed on a mechanical shaker for $24 \mathrm{hr}$. The resulting solution was removed and filtration was carried out through a polyether sulphone (PES) membrane filter $(0.45 \mu \mathrm{m}$ pore size). One $\mathrm{mL}$ of the solution was appropriately diluted using $6.8 \mathrm{pH}$ phosphate buffer and analyzed by HPLC (Waters with Empower 2.0 software).

The following formula is used to calculate the Entrapment efficiency

$$
\text { Encapsulation efficiency }=\left(\frac{\text { Estimated drug content }}{\text { Theoritical drug content }}\right) \times 100
$$

\section{Drug loading study}

About $20 \mathrm{mg}$ of microparticles was dissolved with $2 \mathrm{~mL}$ of dimethylsulphoxide (DMSO) and sonicated for $2 \mathrm{~min}$. Then $2 \mathrm{ml}$ of purified water was added and sonicated for another $2 \mathrm{~min}$. Volume was made up to $20 \mathrm{~mL}$ with purified water, filtered and loaded on HPLC. For drug loading running time $20 \mathrm{~min}$ and column used was inert sustain $4.6 \times 1003.5 \mathrm{u} \mathrm{C}_{18}$.

\section{In vitro drug release study}

Phosphate buffer (pH 7) $9 \mathrm{~mL}$ and $1 \mathrm{~mL}$ diluent (earlier prepared) were added in one of the bottle of rotating bottle apparatus. Entire content of one vial containing leuprolide acetate microspheres was added inside the bottle and closed. Different samples in different rotating bottle for different time intervals were placed in triplicate at 0.071 (12 h), 1, 2, 3 and 4 week (properly labelled). After completion of each time point the content of the bottle was centrifuged for $5 \mathrm{~min}$ at $10,000 \mathrm{rpm}$. The supernatant liquid from the bottle was discarded and $2 \mathrm{~mL}$ of dimethyl sulphoxide (DMSO) was added in the same bottle and sonicated for $2 \mathrm{~min}$ with the addition of $2 \mathrm{~mL}$ water. Then sonicated it for $2 \mathrm{~min}$, volume made up to $20 \mathrm{~mL}$ with distilled water. The content was filtered (with $0.45 \mu$ PVDF) and analysed on HPLC.

\section{Residual Solvent}

Finished formulations were analysed for residual solvent of methylene chloride present by using Agilent 7890 GC with head space sampling option. DMSO was used as diluent for the preparation of sample and standards. Different levels of methylene chloride standard were prepared in DMSO from 1 to $1000 \mathrm{ppm}$ not less than 6 levels. Leuprolide microspheres were dissolved in DMSO at concentration level $5 \mathrm{mg} / \mathrm{mL}$. Nitrogen was used as carrier gas, Nitrogen/air/hydrogen were used as $25 / 340 / 30 \mathrm{~mL} / \mathrm{min}$ and detector temperature was $260^{\circ} \mathrm{C}$, sample and standard injection volume $2 \mathrm{~mL}$ with split ratio of 25 . Temperature gradient for column used as $0-15 \mathrm{~min} 40^{\circ} \mathrm{C}$ and each minute increase by $10^{\circ} \mathrm{C}$ up to $260^{\circ} \mathrm{C}$.

\section{RESULTS AND DISCUSSION}

\section{Pre-formulation studies}

\section{FTIR study}

Fourier transform infrared spectroscopy (FTIR) analysis was performed as a preformulation study to evaluate if there was any interaction between the active ingredient and the excipients. The results of the FTIR data showed that the characteristics absorption peak of the drug obtained at 3267.59of $\mathrm{N}-\mathrm{H}$ stretching, 1744.79 of $\mathrm{C}=\mathrm{O}$ stretching and $1458.55 \mathrm{~cm}^{-1}$ of $\mathrm{C}-\mathrm{N}$ stretching were found to be unaltered in physically mixed sample of active and raw materials. It was also observed that there was no traceable shifting of existing peaks and no additional peaks were also found. From the above result it can be concluded that there was no interaction in between active ingredient and inactive raw materials (Figure 1).

\section{DSC analysis}

The DSC experiments is run $0-220^{\circ} \mathrm{C}$ temperature range and at 10 or $20^{\circ} \mathrm{C} / \mathrm{min}$. The heat flow against temperatures was plotted and the DSC curves were obtained (Figure 2). The melting range can be found out from the onset, peak and endpoint. The Tg of PLGA was found to be 53.06 and that of the microsphere formulation was $56.88^{\circ} \mathrm{C}$. From the results of the DSC data of the final formulation it can be concluded that, 


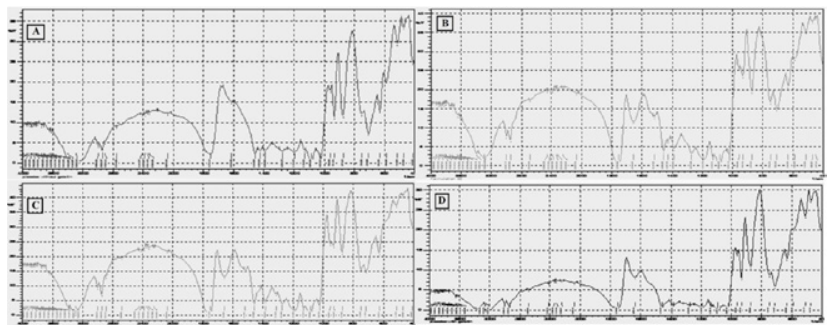

Figure 1: FTIR spectra of A) Leuprolide acetate; B) PLGA (75:25) and Leuprolide acetate mixture; C) Leuprolideacetate and Mannitol; D) Leuprolide acetate and Gelatin.

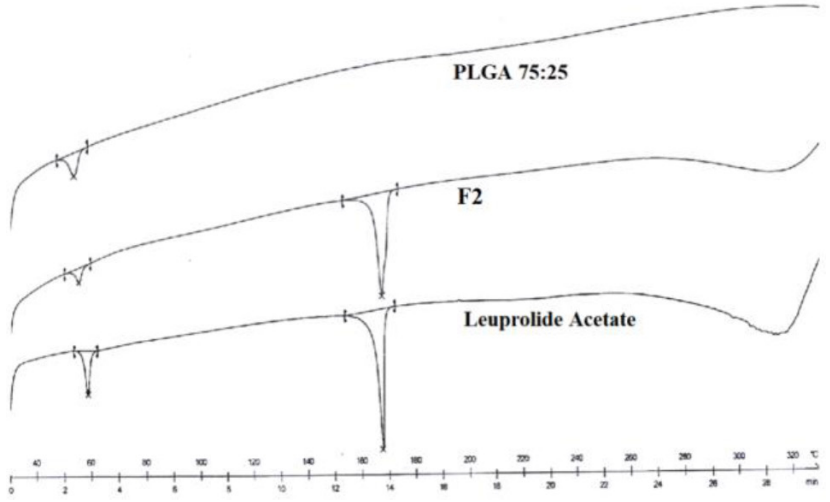

Figure 2: Differential Scanning Calorimetry (DSC).

no chemical interaction exists between the polymers and the drug, thus they are compatible.

\section{Characterization of Microspheres}

F2 showed better drug loading (8.44\%) as compared to F1 (7.8). The entrapment efficiency was 99 and $92 \%$ respectively.

\section{SEM analysis}

SEM photograph of (Figure 3) during initial microspheres, shows that in F2 the surface porosity is uniform compared to that of F1 this may be due to the higher amount of external phase taken in F2.

\section{Advanced SEM analysis}

\section{Drug distribution pattern as per colour coding}

Different colour codes such as red and black were used. Red colour code represented polymer and black was designed to represent the API distribution. From the images, according to the given colour codes more or less uniform drug distribution pattern was observed in the experimental sample. However in final (F2) sample the drug distribution was uniform throughout and in other (F1) sample the distribution pattern was slightly more intense towards periphery. This can be explained possibly due to the higher amount of external phase taken during the in water drying resulting in the slower migration of DCM.

\section{Intense Drug Domains}

This is a cross section of microsphere with different colour codlings instead of microscopy of intact microsphere. In that the colour black represented API, sky blue for polymer, purple colour for surface drug responsible for burst release and yellow for void space respectively. From the Figure 4 it was observed that the distribution pattern of API in polymer was more or less similar in both the batches; however pockets of low drug concentration observed in the F1 batch compared to the F2 final batch.

\section{PLGA Distribution}

Similarly the PLGA distribution was observed and found to be quiet similar in both F1 and F2 batches.

\section{Particle size analysis}

Figure 5 shows the particle size distribution of freezedried formulation F1 and F2. The particle size distribution pattern of freeze dried formulation F1 exhibited as 2.48, 13.37 and $41.96 \mu \mathrm{m}$ of $\mathrm{d} 10, \mathrm{~d} 50$ and $\mathrm{d} 90$ respectively

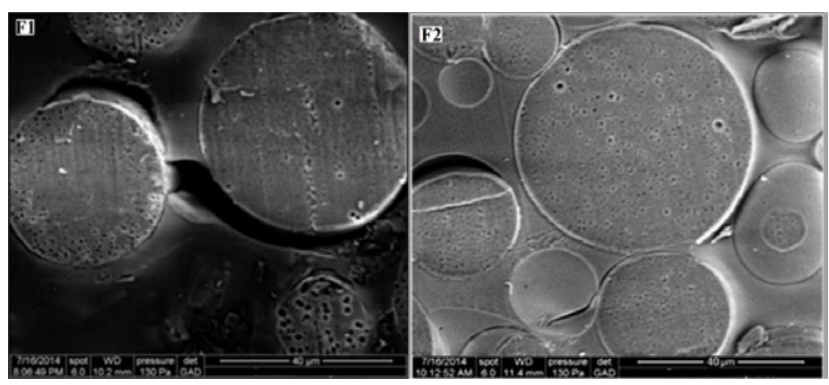

Figure 3: Scanning electron microscopy (SEM) of leuprolide acetate microspheres of F1 and F2.

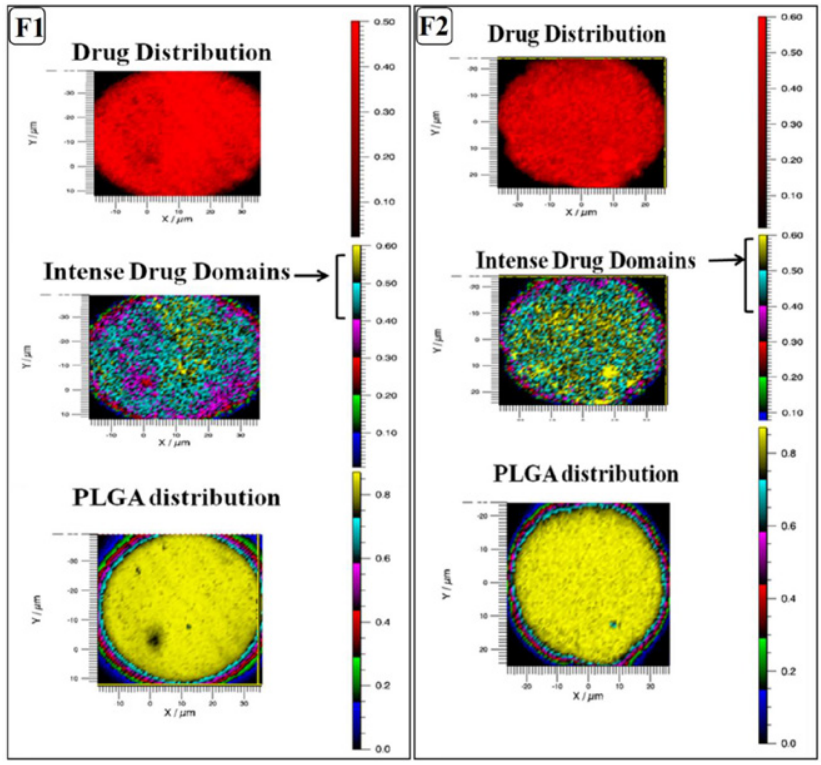

Figure 4: Advanced SEM analysis ofleuprolide acetatemicrospheres F1 and F2. 


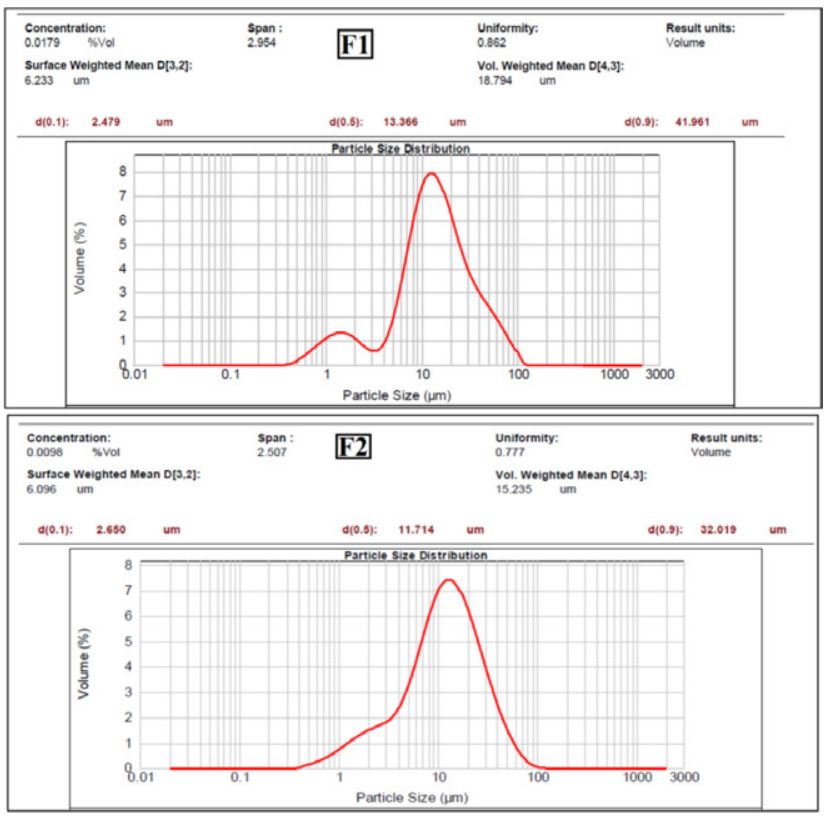

Figure 5: Particle size distribution pattern of freeze-dried formulation F1 and F2.

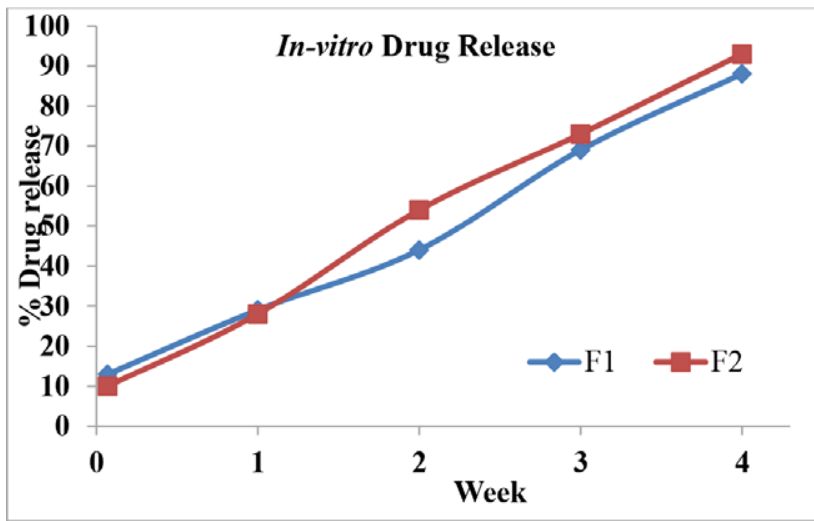

Figure 6: In vitro release profile of leuprolide from encapsulated PLGA microspheres of formulation F1 and F2.

with the mean particle size by volume of 18.79 micron. The mean particle size of by volume of F2 was 15.23 micron with the distribution of were $2.65,11.71$ and $32.02 \mu \mathrm{m}$ of $\mathrm{d} 10, \mathrm{~d} 50$ and $\mathrm{d} 90$ respectively.

Distilled water were used in the manufacturing process and hence not a part of the final formulation.

\section{In vitro drug release study}

Real time in vitro release study showed 93 and $88 \%$ drug release from the formulation batches F2 and F1 respectively after 4 week time (Figure 6). Drug release of F1 was found to be slower as compared to formulation F2.

\section{Residual solvent analysis}

Residual solvents analysed for methylene chloride using Agilent GC system has shown very trace amount of
Table 1: Formulation and characteristics ofleuprolide encapsulated PLGA microspheres prepared by double emulsion solvent evaporation technique.

\begin{tabular}{|c|c|c|c|}
\hline \multicolumn{2}{|c|}{ Formulation $^{a}$} & F-1 & F-2 \\
\hline \multicolumn{2}{|c|}{ Leuprolide acetate(mg) } & 375 & 375 \\
\hline \multicolumn{2}{|c|}{ PLGA (mg) } & 3310 & 3310 \\
\hline \multicolumn{2}{|c|}{ Gelatin $^{b}$} & 65 & 65 \\
\hline \multicolumn{2}{|c|}{ Mannitol (mg) } & 660 & 660 \\
\hline \multicolumn{2}{|c|}{$\mathrm{DCM}(\mathrm{mL})$} & 5 & 5 \\
\hline \multicolumn{2}{|c|}{ PVA 8-88 (g) } & 3 & 4.5 \\
\hline \multicolumn{2}{|c|}{ Purified water $(\mathrm{mL})$} & 1000 & 1500 \\
\hline \multirow{3}{*}{ d value $(\mu \mathrm{m})$} & d 10 & 2.48 & 2.65 \\
\hline & d 50 & 13.37 & 11.71 \\
\hline & d 90 & 41.96 & 32.02 \\
\hline \multicolumn{2}{|c|}{ Drug loading (\%) } & 7.80 & 8.44 \\
\hline \multicolumn{2}{|c|}{ Entrapment Efficiency (\%) } & 92 & 99 \\
\hline \multicolumn{2}{|c|}{$\begin{array}{l}\text { Residual solvent }{ }^{\mathrm{c}} \\
\text { (DCM in ppm) }\end{array}$} & $<1$ & $<1$ \\
\hline
\end{tabular}

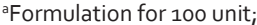

'Bloom of Gelatin = 100;

${ }^{\mathrm{ICH}}$ limit as per quideline $=600 \mathrm{ppm} ;$ $\mathrm{DCM}=$ methylene chloride; PVA = Polyvinyl Alcohol.

almost no detectable (Table 1). Residual solvent was well below the ICH limit as per guideline of $600 \mathrm{ppm}$.

\section{DISCUSSION}

Determination of drug excipient interactions is of paramount significance for any preformulation studies as this provides an indication of compatibility and stability. ${ }^{34}$ The commonly available methods which are employed to determine the interaction between API and raw materials are FTIR, XRD and DSC analysis. ${ }^{35,36}$ In the present study, we evaluated the drug-excipient interaction by FTIR spectroscopy. FTIR spectra assess the drug-excipient interaction at the level of functional groups by determining their vibrational patterns. Here the spectra of leuprolide acetate, mixture of API and PLGA, mixture of API and mannitol, mixture of API and gelatin have been depicted in the results section. After analysing the result, no interaction observed between API and raw materials. Thus the drug and excipients are concluded to be compatible to each other. Here DSC study was conducted to select suitable polymer for microencapsulation. It was observed that $\mathrm{Tg}$ of PLGA $(75: 25)$ is $53^{\circ} \mathrm{C}$, which is very close to the $\mathrm{Tg}$ of the reference listed product earlier reported to be $48.6^{\circ} \mathrm{C} .{ }^{35}$ Therefore PLGA 75:25 was selected so that higher temperature $\left(40^{\circ} \mathrm{C}\right)$ can be applied during water evaporation. From the SEM it was also obvious that the microparticles were properly formed without any sticking 
to the solvent evaporation tank. DSC data of the finished formulation was found to be $55^{\circ} \mathrm{C}$ which was higher than that of the PLGA, due to the interaction between the drug and the excipient. In some literature $\mathrm{Tg}$ was reported to increase with the increase of drug loading. ${ }^{37,38}$

Size, shape and surface characteristics of the microsphere were analysed by SEM. Scanning electron micrograph (Figure 3) of the selected microspheres, F2 and F1 showed overall smooth and spherical surface morphology. In case of F2, the freeze dried microsphere were found to be associated with more homogeneous pores compared to F1. It may be considered to be attributed to the higher amount of outer water phase $\left(\mathrm{W}_{2}\right)$ taken in F2 which lead to easily partitioning DCM in the PVA solution resulting in uniform pore size.

The particle size plays an important role in dispersibility, syringe ability and drug release. Data obtained from particle size analysis (Table 1) indicate that the entire freeze dried formulations were in micro size range, where F2 had the narrowest range of distribution. Most importantly the $\mathrm{d} 90$ value in all the trails was less than $50 \mu$ which will impart good syringe ability. The results suggested that the microparticles were well formed and within the desired distribution range in order to impart one month drug release.

When subjected to high resolution SEM study (Figure 4), it was observed that the distribution pattern of API in polymer was homogenous. However the surface API distribution was abundant in F2. Pockets of low drug concentrations observed in PLGA distribution (F1) presumably because of void spaces.

Loading of leuprolide acetate and the entrapment efficiency within microparticles were estimated to be 8.44 and $99 \%$ for F2 and were 7.8 and $92 \%$ for that of F1 respectively. The encapsulation of API inside polymer core is directly related to the physical and chemical properties of API, solubility of the drug in the solvent, concentration of API, ratio of API to polymer and the temperature during primary and secondary emulsions. Similarly burst release (12 h release) was significantly lowered in F2 compared to F1 due to the higher continuous phase to dispersed phase $(\mathrm{CP} / \mathrm{DP})$ ratio. In all the experimental trials the rpm of Polytron PT 4000 during primary emulsification was kept at 10,000, rpm of Megatron MT 3000 was kept at 8500 and, Injection time of Primary emulsion into the external aqueous phase through the injector port was kept 4 min and post injection stirring time prior to solvent evaporation was kept as $6 \mathrm{~min}$. Similarly solvent evaporation time was also kept constant for all the cycles. Variation was performed in the composition and results were summarized.
The solubility of methylene chloride in water is very less of around $2 \%(\mathrm{v} / \mathrm{v})$. As the quantity of continuous phase was less than the optimal range, methylene chloride diffusion or partitioning rate into the aqueous phase have become slow. So there was great opportunity for the peptide to migrate to the surface of the microsphere. On the contrary if the water phase was large enough to achieve the optimal level, methylene chloride immediately partitioned limiting the migration of active substance to the microsphere surface significantly.

The active ingredient near the surface or its vicinity diffuses out from the microparticles quickly causing initial burst release. Burst release significantly reduced when the continuous phase volume was higher, because the continuous phase containing optimal water concentration led to the quicker precipitation of polymer. Thus the surface of the microspheres F2 became relatively smoother and pores were smaller and uniform compared to F1 as observed in photomicrographs.

\section{CONCLUSION}

Leuprolide acetate loaded PLGA microparticles were formulated using adouble emulsification solvent extraction technique. The finished microparticles have shown the mean particle size by volume was $15.2 \mu \mathrm{m}$ and a suitable PSD range and the pattern of ideal syringe ability with high entrapment efficiency of above $90 \%$. The residual solvent was well within the limit specified by ICH and the particles were spherical in shape with uniform pore distribution and the distribution of API in the polymer matrix was found optimum. The results suggest that the drug released over a month for the microsphere formulation (F2) could be correlated with the testosterone suppression. Therefore, the formulation (F2) will also be tested for in vivo efficacy in an appropriate animal model.

\section{ACKNOWLEDGEMENT}

The authors are grateful to Prof. Manoj Ranjan Nayak, President, Siksha 'O' Anusandhan (Deemed to be University) for laboratory support for this research work across all departments for the fulfilment of the work.

\section{CONFLICT OF INTEREST}

The authors declare no conflict of interest.

\section{ABBREVIATIONS}

PLA: Poly Lactic Acid; PLGA: Poly lactic-co-glycolic acid; LAI: Long acting release Injectable; SEM: Scanning electron microscopy; PDI: Poly dispersity Index. 


\section{REFERENCES}

1. Landis SH, Murray T, Bolden S, Wingo PA. Cancer statistics, 1998. CA: A Cancer Journal for Clinicians. 1998;48(1):6-29.

2. Garnick MB, Fair WR. Combating prostate cancer. Scientific American. 1998;279(6):74-83.

3. Baskar R, Lee KA, Yeo R, Yeoh KW. Cancer and radiation therapy: Current advances and future directions. International Journal of Medical Sciences. 2012;9(3):193.

4. Alagusundaram M, Chetty MS, Umashankari K, Badarinath AV, Lavanya C, Ramkanth S. Microspheres as a novel drug delivery system: A review. International Journal of Chem Tech Research. 2009;1(3):526-34.

5. Cook T, Sheridan WP. Development of $\mathrm{GnRH}$ antagonists for prostate cancer: New approaches to treatment. The Oncologist. 2000;5(2):162-8.

6. Schally AV, Comaru-Schally AM. Rational use of agonists and antagonists of luteinizing hormone-releasing hormone ( $\mathrm{LH}-\mathrm{RH})$ in the treatment of hormonesensitive neoplasms and gynaecologic conditions. Advanced Drug Delivery Reviews. 1997;28(1):157-69.

7. Greer J. LHRH Antagonists. Integration of Pharmaceutical Discovery and Development: Case Histories. 1998;31(11):131.

8. Okada $\mathrm{H}$. One-and three-month release injectable microspheres of the LH$\mathrm{RH}$ superagonist leuprorelin acetate. Advanced Drug Delivery Reviews. 1997;28(1):43-70.

9. Hutchinson FG, Furr BJ. Biodegradable carriers for the sustained release of polypeptides. Trends in Biotechnology. 1987;5(4):102-6.

10. Erb K, Pechstein B, Schueler A, Engel J, Hermann R. Pituitary and gonadal endocrine effects and pharmacokinetics of the novel luteinizing hormonereleasing hormone antagonist teverelix in healthy men-a first-dose-inhumans study. Clinical Pharmacology and Therapeutics. 2000;67(6):660-9.

11. Wilson AC, Vadakkadath MS, Bowen RL, Atwood CS. Leuprolide acetate: A drug of diverse clinical applications. Expert Opinion on Investigational Drugs. 2007;16(11):1851-63.

12. Merseburger AS, Björk T, Whitehouse J, Meani D. Treatment costs for advanced prostate cancer using luteinizing hormone-releasing hormone agonists: A solid biodegradable leuprorelin implant versus other formulations. Journal of Comparative Effectiveness Research. 2015;4(5):447-53.

13. Uhlig T, Kyprianou T, Martinelli FG, Oppici CA, Heiligers D, Hills D, et al. The emergence of peptides in the pharmaceutical business: From exploration to exploitation. EuPA Open Proteomics. 2014;1(4):58-69.

14. Periti P, Mazzei T, Mini E. Clinical pharmacokinetics of depot leuprorelin. Clinical Pharmacokinetics. 2002;41(7):485-504.

15. FDA, LUPRON DEPOT (leuprolide acetate for depot suspension). 2013. https://www.accessdata.fda.gov/drugsatfda_docs/label/2014/020517s036_ 019732s041lbl. pdf

16. Okada H, Heya T, Igari $\mathrm{Y}$, Ogawa $\mathrm{Y}$, Toguchi H, Shimamoto $\mathrm{T}$. One-month release injectable microspheres of leuprolide acetate inhibit steroidogenesis and genital organ growth in rats. International Journal of Pharmaceutics. 1989;54(3):231-9.

17. Okada H, Heya T, Ogawa Y, Toguchi H, Shimamoto T. Sustained pharmacological activities in rats following single and repeated administration of once-a-month injectable microspheres of leuprolide acetate. Pharmaceutical Research. 1991;8(5):584-7.

18. Benita S. Microencapsulation: Methods and industrial applications. Crc Press. 2005.

19. Wang J, Wang BM, Schwendeman SP. Mechanistic evaluation of the glucoseinduced reduction in initial burst release of octreotide acetate from poly ( $D$, L-lactide-co-glycolide) microspheres. Biomaterials. 2004;25(10):1919-27.

20. Yang YY, Chung TS, Bai XL, Chan WK. Effect of preparation conditions on morphology and release profiles of biodegradable polymeric microspheres containing protein fabricated by double-emulsion method. Chemical Engineering Science. 2000;55(12):2223-36
21. Mao S, Xu J, Cai C, Germershaus O, Schaper A, Kissel T. Effect of WOW process parameters on morphology and burst release of FITC-dextran loaded PLGA microspheres. International Journal of Pharmaceutics. 2007;334(1-2): 137-48.

22. Yushu $\mathrm{H}$, Venkatraman $\mathrm{S}$. The effect of process variables on the morphology and release characteristics of protein-loaded PLGA particles. Journal of Applied Polymer Science. 2006;101(5):3053-61.

23. Li WI, Anderson KW, Mehta RC, Deluca PP. Prediction of solvent removal profile and effect on properties for peptide-loaded PLGA microspheres prepared by solvent extraction/evaporation method. Journal of Controlled Release. 1995;37(3):199-214.

24. Blehn GF, Ernsberger ML. Polyvinyl alcohol as an emulsifying agent. Industrial and Engineering Chemistry. 1948;40(8):1449-53.

25. Jobmann M, Rafler G, Sagala J, Gross I, inventors; Schill, Seilacher GmbH, assignee. Microcapsules used for producing rubber and method for their production. United States Patent US 7,947,370. 2011.

26. Jain R, Shah NH, Malick AW, Rhodes CT. Controlled drug delivery by biodegradable poly (ester) devices: Different preparative approaches. Drug Development and Industrial Pharmacy. 1998;24(8):703-27.

27. Yang $Q$, Owusu-Ababio G. Biodegradable progesterone microsphere delivery system for osteoporosis therapy. Drug Development and Industrial Pharmacy. 2000;26(1):61-70.

28. Maria TM, DeCarvalho RA, Sobral PJ, Habitante AM, Solorza-Feria J. The effect of the degree of hydrolysis of the PVA and the plasticizer concentration on the color, opacity and thermal and mechanical properties of films based on PVA and gelatin blends. Journal of Food Engineering. 2008;87(2):191-9.

29. Jeffery H, Davis SS, O'Hagan DT. The preparation and characterization of poly (lactide-co-glycolide) microparticles. II. The entrapment of a model protein using a (water-in-oil)-in-water emulsion solvent evaporation technique. Pharmaceutical Research. 1993;10(3):362-8.

30. Bilati U, Allémann E, Doelker E. Poly ( $D$, L-lactide-co-glycolide) proteinloaded nanoparticles prepared by the double emulsion method-processing and formulation issues for enhanced entrapment efficiency. Journal of Microencapsulation. 2005;22(2):205-14.

31. Shi NQ, Zhou J, Walker J, Li L, Hong KY, Olsen KF, et al. Microencapsulation of luteinizing hormone-releasing hormone agonist in poly (lactic-co-glycolic acid) microspheres by spray drying. Journal of Controlled Release. 2020.

32. Sahoo RN, Ananya D, Kataria V, Mallick S. Solvent-free Hot Melt Extrusion Technique in Improving Mesalamine Release for Better Management of Inflammatory Bowel Disease. Indian $\mathrm{J}$ of Pharmaceutical Education and Research. 2019;53(4s):s554-62.

33. Li X, Zhang Y, Yan R, Jia W, Yuan M, Deng X, et al. Influence of process parameters on the protein stability encapsulated in poly-DL-lactide-poly (ethylene glycol) microspheres. Journal of Controlled Release. 2000;68(1):4152.

34. Mukherjee B, Patra B, Layek B, Mukherjee A. Sustained release of acyclovir from nano-liposomes and nano-niosomes: an in vitro study. International Journal of Nanomedicine. 2007;2(2):213.

35. Tewes F, Tajber L, Corrigan OI, Ehrhardt C, Healy AM. Development and characterisation of soluble polymeric particles for pulmonary peptide delivery. European Journal of Pharmaceutical Sciences. 2010;41(2):337-52.

36. Rudra A, Deepa RM, Ghosh MK, Ghosh S, Mukherjee B. Doxorubicinloaded phosphatidylethanolamine-conjugated nanoliposomes: in vitro characterization and their accumulation in liver, kidneys and lungs in rats. International Journal of Nanomedicine. 2010;5:811.

37. Zhou J, Hirota K, Ackermann R, Walker J, Wang Y, Choi S, et al. Reverse engineering the 1-month Lupron Depot@. The AAPS Journal. 2018;20(6):105.

38. Okada H, Doken Y, Ogawa Y, Toguchi H. Preparation of three-month depot injectable microspheres of leuprorelin acetate using biodegradable polymers. Pharmaceutical Research. 1994;11(8):1143-7. 
PICTORIAL ABSTRACT

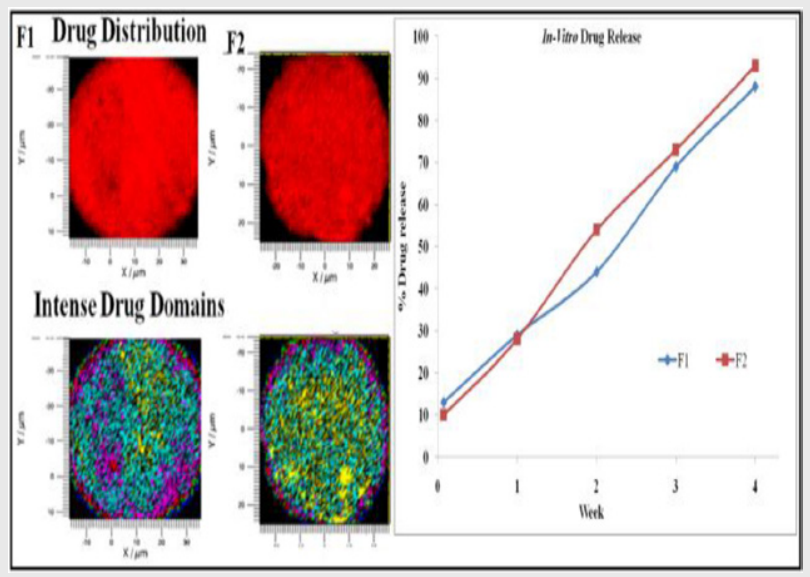

\section{SUMMARY}

Leuprolide acetate loaded PLGA spherical microparticles were produced formulated using a double emulsification solvent extraction technique. With the finished microparticles have shown high entrapment efficiency of above $90 \%$ and the mean particle size distribution of suitable range and the pattern of ideal syringe ability. Uniform pore distribution and the distribution of API in the polymer matrix was found in the produced microspheres. The drug release uniformly sustained over a month and could be correlated with the testosterone suppression.

\footnotetext{
About Authors

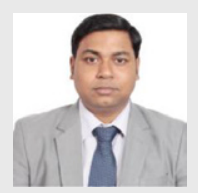

Soumya Ranjan Satapathy, M.Pharm, has been working in pharmaceutical area for more than 10 years including Glenmark Pharmaceuticals Ltd. and Bharat Serums and Vaccines Ltd., as Formulation Scientist in NDDS Technologies, primarily focusing on Biodegradable polymer based long acting release Injectable such as microspheres, implants and in situ gelling delivery systems. Currently he is doing Ph.D at School of Pharmaceutical Sciences, Siksha 'O' Anusandhan (Deemed to be University), Bhubaneswar, Odisha, India. His research area of interest is Formulation and Development of PLGA and Lipid based Drug Delivery Systems.

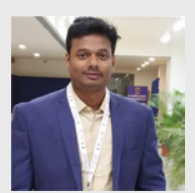

Rudra Narayan Sahoo, M.Pharm, Assistant Professor at Centurion University of Technology and Management, Bhubaneswar, Odisha, India. Continuing Ph.D at Siksha'O' Anusandhan (Deemed to be University), Bhubaneswar, India. His research area of interest is Formulation and Development and Drug Delivery Systems.

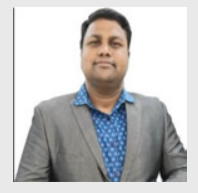

Biswaranjan Satapathy, MSc (Applied Physics) has been working in Pharmaceutical Research for more than 5 years in analytical characterization department, primarily focusing on topical, injectable and ophthalmic formulation characterization. Currently he is the Manager at Orbicular Pharmaceutical Technologies Pvt Ltd, Hyderabad, India, leading the pharmaceutical characterization department. $\mathrm{He}$ is a rheology expert and current research area of interest is the method development and validation of Particle size, zeta potential, Viscometry and other rheological critical quality attributes.

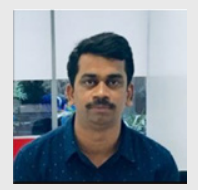

Ramachandrarao Immani, M.Sc., M.Tech., has been working in pharmaceutical area for more than 11 years including GlaxoSmithKline, Novartis, Sun Pharma and Glenmark Pharmaceuticals Ltd as an Analytical scientist. Expertise in analytical characterisations, reverse engineering of different dosage forms Liquid, solid and semi solids. Currently he is doing Ph.D at Annamalai University, Annamalai Nagar, Chidambaram, Tamil Nadu, India. His research area of interest is Analytical characterisations of drug products and degradation products in drug products and drug substances.

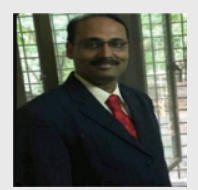

Lalatendu Panigrahi, M.Pharm, Ph.D has been working in pharmaceutical research for more than 20 years including Sun Pharmaceuticals, Glenmark Pharmaceuticals Ltd and Dr Reddys Laboratories Ltd, primarily focusing on topical drug delivery systems. Currently he is the Chief Scientific Officer and heading the formulation $R \& D$, analytical $R \& D$ and Regulatory affairs at EncubeEthicalsPvt. Ltd., Mumbai, India. His research area of interest is bioavailability enhancement and lipid based Drug Delivery Systems for topical dosage forms. He has 8 patents and 15 publications in the pharmaceutical field.
} 
Subrata Mallick (M Pharm, PhD, PGDBM, FIC) is a life member of Association of Pharmaceutical Teachers of India and Indian Pharmaceutical Association. At present he is the Professor and Heading the Department of Pharmaceutics, School of Pharmaceutical Sciences, Siksha'O' Anusandhan (Deemed to be University), Bhubaneswar, India. He is the reviewer of Elsevier, Wiley, Informa Healthcare, Taylor and Francis, Bentham Science, Springer, IEEE Xplore, Dovepressetc. and editorial board member of several International Journals of America, Canada, UK, Thailand, India etc. He is also a member of doctoral committee of several universities. His current research areas of interest are: Ocular Drug Delivery Systems, Drug Stabilisation and Kinetics, Mucosal Delivery, Powder Compaction etc. More than 160 number of full research papers and conference proceedings are published in International and National levels under his guidance.

Cite this article: Satapathy SR, Sahoo RN, Satapathy B, Immani R, Panigrahi L, Mallick S. Development and Characterization of Leuprolide Acetate Encapsulated PLGA Microspheres for Parenteral Controlled Release Depot Injection. Indian J of Pharmaceutical Education and Research. 2021;55(1):107-16. 